\title{
Impact of Employee Engagement on Performance at A Pump Supplier
}

\author{
Stephen Bale, Alan Pillay \\ MANCOSA Graduate School of Business, Durban, South Africa \\ publications@mancosa.co.za \\ ${ }^{*}$ Corresponding author
}

\author{
Keywords: \\ Commitment Levels, \\ Communication Channels, \\ Relationship Management
}

\begin{abstract}
The study aimed to investigate the impact of employee engagement on performance at a South African pump supplier. The research adopted a qualitative study and a nonprobability purposeful sampling technique with a target population of ten employees at the company. It examined the factors that contributed to the development of employees' engagement and the effect of engagement on employee performance. The research instrument used interview and was analyzed qualitatively. Key findings revealed that the employees at the company are disengaged due to ineffective leadership, poor communication between management and employees, lack of a recognition system, inadequate employee participation in decision-making, and an absence of a strategic and coordinated approach to the employees' wellbeing. Recommendations were that the organization should allow its workforce to provide input in the decision-making of the organization, improve effective and transparent internal communication, employee development and empowerment, and an effective recognition system. Leaders should support the effective utilization of employee skills and capabilities. The study showed that there is a relationship between employee engagement and performance due to the lack of employee engagement that lowered employee capability and affected the organization's bottom line. Designing and implementing an effective employee engagement strategy is, therefore, desirable to the employee and organizational performance.
\end{abstract}

\section{INTRODUCTION}

Employee engagement has become a global point of interest for many executives and organizations. In the competitive pump industry, business leaders are aware that having high-performing employees is crucial for growth and existence. They acknowledge that a highly engaged employee can increase productivity and performance while reducing costs related to hiring and retention and increasing their competitive advantage. In the traditional manufacturing industry, there is a tendency to emphasize process improvement and workforce output, rather than employee wellbeing, and profit rather than customer-supplier relationship management. This research aimed to investigate the effects and 
challenges faced by the pump supplier by embarking on employee engagement as a strategy to improve the organization's performance and strengthen its market share.

Employee engagement has become a significant strategy for many organizations to improve their performance, customer satisfaction, and competencies. To create any type of positive change, organizations need to know what is happening within. The company also faced challenges like other manufacturing organizations with regards to poor communication, lack of employee participation, lack of employee recognition and poor performance appraisals, and a low level of diversity, which in turn results in poor performance within the organization. These challenges resulted in the company losing market share within the pump industry due to late deliveries and the inability to retain staff which impacts their bottom-line, their performance, and customer satisfaction. This condition has influenced the company to embark on employee engagement strategies to improve customer satisfaction and performance in the organization. The findings of the research will provide management with an indication of the effectiveness of an employee engagement strategy in driving organizational strategic objectives and performance.

To determine solutions for the foregoing the following objectives were proposed: (1) Determine the factors that affect employee engagement; (2) Determine the effects of employee engagement on employee performance. Make recommendations to help the company make rational decisions regarding organizational performance.

\section{LITERATURE REVIEW}

Cattermole, Johnson, and Jackson (2014:81) advocated that employee engagement is a workplace approach designed to ensure that employees are committed to the business and their values and goals. Conversely, Hewitt (2018:2) defined employee engagement as "the level of an employee's psychological investment in their organization". Gallup (2013:7) defined employee engagement as the involvement with an enthusiasm for work, thus the emotional commitment employees feel towards their organization and the activities they take to ensure the organization's success is determined by such enthusiasm. Deloitte (2016:11) described engagement as "how people feel about the way things work around here," when describing employees' level of engagement. Their study further states that engagement includes meaningful work and jobs, management practices and behaviors, the work environment, development and growth opportunities, leadership trust, and flexible mobile working.

The above definitions of employee engagement suggest that employee engagement refers to the involvement, passion, dedication, and enthusiasm at work and workplace and external factors that affect workforce state of wellbeing effectively achieving desirable organizational strategic objectives. The company needs to have a clear understanding of its workforces to successfully implement employee engagement strategies concerning its mission and vision.

\section{Employee Engagement and Organisational Performance}

Sharmila (2013:113) summarised that employee engagement is a positive approach held by employees towards the organization, its objectives, and values. The notion of engagement is rapidly gaining popularity as it impacts organizations in both positive and negative ways. Significant attention has been given to the linkage of employee engagement to the financial results of organizations.

According to Hewitt (2018:2), the engaged employee consistently demonstrates three behaviors that enhance organizational performance. They are expected to say by speaking confidently and positively about the company to all stakeholders. They are also expected to stay by having an intense sense of belonging and desire to be a part of the organization, and lastly, to strive by giving their best efforts to support the organization's quest to succeed. 


\section{The Cost of Disengaged Employees on Organisational Performance}

Despite the widespread acknowledgment of the significance of employee engagement to organizations, reports find astonishingly low levels of engagement globally. Gallup (2013:6) showed that only thirteen percent of the workforce working for organizations globally are engaged. The survey further states that organizations that invested in the employee engagement strategy have realized the value of the investment. A survey by Gallup (2013:56) in South Africa had revealed some disturbing findings, such as, only nine percent of the South African workforce is actively engaged, and of the nighty-one percent who were disengaged, forty-five percent were actively disengaged, meaning that they are negative about their work environment.

\section{Culture and Employee Engagement}

Organizational culture is one of the important sources of competitive advantage and organizational health, as it positively and negatively affects organizational performance and behavior. Grobler, Carrell, and Wärnich (2011:638) defined culture as "the shaping of the mind that distinguishes the members of a group or category of people from those of another". They further state that culture is expressed as the collective values, norms, traditions, myths, and institutions that are characteristic among members of the organization.

\section{METHOD}

The study aimed to identify any causal links between employee engagement and organizational performance. Therefore, the study is explanatory as the aim is to investigate, explore and measure relationships between dependent and independent variables. A survey in the form of an interview was therefore adopted.

The target population was drawn from non-management employees, which consisted of both skilled and semiskilled employees within the company. The total number comprised 255 employees from the Sales, Engineering, Planning, Production, Procurement, and Dispatch departments. Ten employees were selected within the organization. The study used a non-probability purposeful sampling technique due to access to the respondents working at the company, with the aid of pre-defined criteria for selection to elicit responses from employees who are likely to relinquish most of the information on the research topic (Maree, Creswell \& Ebersohn, 2010:79).

\section{Ethical Considerations}

The ethical considerations implemented in the study included ensuring participants were given informed consent and no harm came to participants. Confidentiality and anonymity were assured and permission was obtained from the Head of Operations and the HR Manager at the company.

\section{RESULTS AND DISCUSSION}

Ten employees of the company represented a reasonable sample in qualitative studies, which comprised four female $(40 \%)$ and six male participants $60 \%$ of the sample. $20 \%$ had acquired a university degree, whereas $30 \%$ a diploma. $20 \%$ have college certificates while $30 \%$ had a matric certificate respectively.

The participants were drawn from the following departments: Production, Sales, Engineering, Planning, Procurement, Finance, Human Resource, and Dispatch departments. The majority of the employees were in the Production Department, $(30 \%)$, whereas the remaining $70 \%$ were distributed equally $(10 \%)$ among the seven departments therefore equitably balanced in terms of staff participation.

The respondents reported 0-5 years of service which comprised four (40\%), 6-10 years comprised three (30\%), 11-15 years one (10\%), and lastly two $(20 \%)>20$ years of service. No participants were 
from the age group between 18 and 29 years. Participants were mature and experienced to respond relevantly to the research problem.

\section{Core Themes}

The results from the data analysis derived the following core themes: (1) Inadequate communication within the organization, (2) Organisation lacks systematic recognition programs,(3) Inadequate trust in leadership, (4) Organisation lack of transparency in skills development and succession planning of employees, (5) Organisation lack of a strategic and coordinated approach to employees' well-being, (6) Organisation strategic goals and objectives clearly defined, (7) Inadequate employee participation in decision-making, (8) Employees' commitment to the organization, (9) Communication flow among employees and management and (10) Lack of supportive work environment. These core themes describe both the factors affecting employee engagement and the effects of employee engagement on employee performance as per objectives 1 and 2 .

\section{Effect of employee engagement}

Inadequate communication within the organization: The respondents suggested that management was not adequately communicating with them, due to a lack of effective communication channels and ineffective structure currently used, and also management is not completely honest and transparent.

\section{Organization lack systematic recognition programs}

A well-executed employee recognition program can influence many facets of the organization from self-esteem, to productivity, engagement, and even retention. However, the respondents interviewed suggested the company lacks a systematic reward or recognition system.

\section{Inadequate trust in leadership}

When the workforce feel they cannot trust management they feel unsafe, and then devote more initiative to self-defense and career hunting than performing their responsibilities, as indicated by the respondents who reported that their line manager does not inspire them and some continually find fault.

Organization lack of transparency in skills development and succession planning of employees

The respondents stated that the organization lacks transparent succession planning, as they are not aware of the initiative and none of them has ever been called by management to discuss succession planning.

\section{Determine the Effects of Employee Engagement on Employee Performance}

To ascertain the effect engagement has on employee performance, a lack of employee engagement was considered which has implications for employee and organization's performance such as employee involvement in decision-making, communication flow between management and employees, employees' lack of commitment to the organization, quality of relationships between employee and management.

\section{Inadequate employee participation in decision making}

Inadequate workforce participation in decision-making, in turn, leads to low levels of employee commitment, trust in leadership, commitment, and turnover intentions which have negative impacts on organizational performance. Respondents believe they are not given opportunities to explore opportunities and challenges. Another said no KPI had been implemented.

\section{Employees lack the commitment to the organization}

Employee commitment appears to be a critical factor in achieving organizational success. Employees with low levels of commitment will do only the minimum. They do not put their hearts into the work and mission of the organization, which eventually affects their performance. Reports of lack of support from management and coming to work merely for the salary cheque led to demotivated employees. 


\section{Unsupportive work environment}

Respondents were asked what would make them consider changing jobs. The answers from the respondents varied. However, a similar pattern of meaning with regards to the lack of support from management and salary and job satisfaction makes them consider leaving the company. Respondents felt that an attractive offer would make them leave.

\section{CONCLUSIONS}

Findings revealed that the employees generally have negative feelings regarding the leadership style they are receiving from their management managers. It was also evident that the management style impacted the employees' self-confidence, which subsequently affected the performance of the employees and the organization.

The effects of a lack of effective communication between top management and employees and amongst the employees themselves affect employee performance at the company. Respondents agreed that a lack of effective communication will affect strategy implementation of the employee engagement system at the company. This is because the organization does not provide employees with opportunities to make inputs in decision-making in the organization.

Some challenges were evident related to employee engagement at the company. These included the lack of competent managers at all levels and ineffective communication flow in the organization between senior management, middle management, and employees. There is also a lack of an effective organizational structure, effective administration systems, and sufficient reward and recognition systems. Lastly, the lack of transparent succession planning and skills development in the organization leads employees to perform their work according to their personal views, thus compromising the implementation of employee engagement strategies.

One hundred percent (10) of the respondents indicated that they knew what is expected of them at work and have the right tools to carry their duties efficiently. This has led to the conclusion that the skills and capabilities of employees within the company are not fully utilized from a resource perspective.

Management should build trust and support the importance of employee contributions towards attaining goals and objectives through participation and transparency. A smaller percentage indicated that there is someone at work who encourages and supports their development.

The company lacks recognition programs. Ten (100\%) participants supported the need for management to reward and appreciate dedicated employees. Some respondents suggested that since employed at the organization they never received recognition and further that a mere acknowledgment and appreciation from management is worth more than financial compensation. The findings may assist management in the development of employee engagement by incorporating incentives and acts of appreciation to fulfill the physical, intellectual, and psychological needs of the workforce which has a direct link to employee performance. The findings may contribute to minimizing the gap of knowledge among leadership concerning strategies to effectively manage employee commitment and support continuous training and skills development.

\section{Conclusion}

The findings indicated that the organization needs to streamline all the pertinent factors before implementing employee engagement as a strategy to improve employee and organizational performance. Participants did not demonstrate the three behaviors that enhance employees and organizational performance as indicated by the Hewitt Employee Engagement Model. The model indicated that employees are expected to speak confidently and positively about the company to all 
stakeholders. They are also expected to stay by having an intense sense of belonging and desire to be a part of the organization, and lastly, to strive by giving their best efforts to support the organization's need to succeed.

Out of the seven main factors, which were effective leadership, skills development, effective communication, employee recognition, employee satisfaction, succession planning, and employee wellbeing, there were some gaps in the literature and findings. Four factors proved the most influential to the employees of the company. They were effective communication between management and employees and amongst the employees, transparent succession planning, employee recognition, and lastly, effective leadership and the relationship they have with their workers.

The second aim of this research was to determine the effects engaged employees have engagement on employee performance. The following effects were revealed that had negative or positive effects at the company, namely lack of employees' participation in organization decisions, lack of employees' commitment to the organization, communication flow among employees and management, lack of supportive work environment, lack of teamwork and clarity about expectations. The above finding had a negative influence on employees' performance and hence management needs a better understanding of these challenges before the development of employee engagement as a strategy to stay competitive.

Overall the company lacks satisfactory systems in place for the development of effective employee engagement strategy to enhance employees' and organizational performance. However, some work has been done concerning having the right tools to do the tasks. Regarding factors that affect employee engagement strategy, it was found that effective communication, goal clarity, recognition, and employee empowerment are some of the engagement factors that an organization can introduce during the implementation of engagement strategy to engage the workforce. The company was found to lack charismatic leadership, especially middle management, who are not piloting the organization in the right direction. It can, therefore, be concluded that for the company to effectively implement employee engagement as a strategy, management should focus on the above factors that negatively impact development.

For the company to stay competitive, it is imperative to constantly advance its employees' performance. Therefore, employees should be more involved in decision-making and motivated to remain committed to the organization. It can, therefore, be concluded that the company needs to have committed, willing employees to successfully achieve its strategic objectives.

All ten respondents stated that employees have the right tools needed to do their tasks well. It can, therefore, be concluded that having the right tools does not improve employee performance without effective communication and support from management. Other future research could focus on: (1) The effect of culture on employee engagement; (2) Training and development for middle managers to improve employee engagement.

This study will assist management to better understand the role they need to play during the development of engagement strategy and the need to know and understand the importance of employee engagement on organizational performance. In conclusion, the positive development of the study was that the workforce asked for a more transparent, authentic, and understandable form of communication, more opportunities to actively participate in decision-making, and lastly, the development of leaders to perform their roles actively and proficiently.

\section{Recommendation}

Employee engagement strategies recommend that leaders search beyond the status quo to recognize innovative tools, flexible working arrangements, and value-adding resources to stay competitive in this universal economic environment. The following actions are recommended: 


\section{Employee engagement strategies at the company}

The company's management and leaders need to focus more on engagement strategies that support the organization's effectiveness concerning higher productivity, profitability, quality, customer satisfaction, employee retention, and greater adaptability. The company should acknowledge that disengaged employees not only harm employee morale, they are also damaging to the organization's financial position. Therefore, management must continuously take the pulse of employee engagement levels in their organizations and proactively take management decisions to ensure that middle management understands and supports boosting those levels to impact organizational results and engage the disengaged, by providing support through coaching and dialogue forums.

\section{Improve communication between management and employees}

The company needs to acknowledge that internal communication is significant for building a culture of friendship between management and employees, to effectively engage employees to achieve the organization's goals and objectives. When employees get extensive information about the company's business and performance, they feel more valued and develop a sense of entitlement, thus creating more opportunities for dialogue, making communication modern and interactive, and providing opportunities for employee participation.

\section{Transparent succession planning}

Transparent succession planning should be based on a systematic process molded on what effective leaders do differently, focusing on building effective capabilities, knowledge, and leadership style to increase employee engagement. This can be achieved through identifying critical positions at the organization, determining the skills required for these key positions, identifying and assessing potential successors, and lastly committing to developing internal talent, mentoring, and monitoring the progress.

\section{Effective skill development initiatives}

Management should develop a clear, effective skills development program to support succession planning through analyzing skills requirements within the organization, creating effective action plans for developing employee skills, draw timelines for the development of each required skill, and, lastly, implement skills development initiatives.

\section{Employee recognition}

Management should develop meaningful recognition, incentives, and rewards systems to ensure a sense of return on investment for employees. This can be achieved through feedback on employees' performance, celebrating employees' achievement, anniversaries, and long service awards.

\section{Enabling employees participation in decision-making}

The company should give its employees opportunities for active participation in decision-making in the organization. The above can be achieved by setting up and implementing discussion forums, providing an interactive ideas management system, and, lastly, developing an internal social network to release their employees' capabilities.

\section{Managers support to improve}

The company should develop management development programs to assist them to perform their roles more effectively, as this currently does not always happen in all areas of the organization. The above can be achieved by introducing and implanting a modern development and training plan and providing support through coaching and dialogue forums.

\section{Recommendations for future research}

The results, implications, and recommendations outlined in this study may positively contribute to the current body of knowledge, and future studies regarding strategies for manufacturing industry leaders needing to implement effective employee engagement to achieve its strategic goals. The inability of 


\section{IJ-MDS International Journal of Multi Discipline Science (IJ-MDS) \\ Vol. 4 No. 1 (2021) \\ e-ISSN: 2615-1707. Page: 1-8}

the participants to articulate their knowledge and understanding of the study topic was not manifested. However, future researchers might consider including management as part of the participants to obtain a broader perspective and most relevant evidence and enrich the quality of interview data collected. The entire pump industry could be the subject of research. Lastly, it is recommended that additional studies be conducted on the relationship between employee engagement and employee performance to determine whether the same results can be found in other sectors.

\section{REFERENCES}

Cattermole, G., Johnson, J., \& Jackson, D. (2014). Employee Engagement Create A Brighter Economic Future at Jupiter Hotels. Strategic HR Review, 13(2), 81-85.

Deloitte, Deloitte. (2016). Employee Engagement Perspectives: Engaging the Workforce. [Online] Available: www.deloitte.com/engagepath. (Accessed: 17 March 2018).

Gallup. (2013). State of the Global Workforce: Employee Engagement Insight for Business Leaders Worldwide. pp. 7-25.

Grobler, P.A., Carrell, M.R., \& Wärnich, S. (2011). Human resource management in South Africa. 4th $e d$. Pretoria: Cengage Learning.

Hewitt, Aon. (2018). Trends in Global Employee Engagement: Employee Engagement in Theory and

Practice.

[Online].

Available:

https://www.aonhewitt.com.au/AON.Marketing/media/Australia/pdf/Resources/Reports\%20a nd\%20research/2018-Trends-in-Global-Employee-Engagement.pdf. (Accessed: 17 March 2018).

Maree, K., Creswell, J.W., \& Ebersohn, L. (2010). First step in research. 5th ed. Pretoria: Van Schaik.

Sharmila, J.V. (2013). Employee engagement - An approach to organizational excellence. International Journal of Social Science \& Interdisciplinary Research, 112-116. 